\title{
The ABCG2 Polymorphism rs2725220 Is Associated with Hyperuricemia in the Korean Population
}

\author{
Jae Woong Sull ${ }^{1}$, Seung-Ju Yang ${ }^{2}$, Soriul $\mathrm{Kim}^{3}$, Sun Ha Jee ${ }^{3 *}$ \\ ${ }^{1}$ Department of Biomedical Laboratory Science, College of Health Sciences, Eulji University, Seongnam 461-713, Korea, \\ ${ }^{2}$ Department of Biomedical Laboratory Science, Konyang University, Daejeon 302-718, Korea, \\ ${ }^{3}$ Department of Epidemiology and Health Promotion, Institute for Health Promotion, \\ Graduate School of Public Health, Yonsei University, Seoul 120-752, Korea
}

\begin{abstract}
Elevated serum uric acid levels are associated with a variety of adverse health outcomes, including gout, hypertension, diabetes mellitus, metabolic syndrome, and cardiovascular diseases. Several genome-wide association studies on uric acid levels have implicated the ATP-binding cassette, subfamily G, member 2 ( $A B C G 2$ ) gene as being possibly causal. We investigated an association between the single-nucleotide polymorphism (SNP) rs2725220 in the $A B C G 2$ gene and uric acid levels in the Korean population. A total of 991 subjects in Seoul City were used for a replication study with $A B C G 2$ SNP rs2725220. The rs2725220 SNP in the $A B C G 2$ gene was associated with mean uric acid levels (effect per allele $0.25 \mathrm{mg} / \mathrm{dL}, \mathrm{p}$ $<0.0001$ ). Subjects with the GC/CC genotype had a 1.78-fold (range, 1.22- to 2.62-fold) higher risk of having abnormal uric acid levels ( $\geq 7.0 \mathrm{mg} / \mathrm{dL}$ ) than subjects with the GG genotype. When analyzed by gender, the association with ABCG2 was stronger in men than in women. The association with ABCG2 was much stronger in male subjects with body mass index (BMI) $\geq 26.4$ (odds ratio, 5.09 ; $95 \%$ confidence interval, 2.41 to 10.8 ) than in male subjects with BMI < 26.4. This study clearly demonstrates that genetic variations in $A B C G 2$ influence uric acid levels in Korean adults.
\end{abstract}

Keywords: $A B C G 2$, genetic polymorphism, uric acid

\section{Introduction}

Elevated serum uric acid levels are associated with a variety of adverse health outcomes, including gout, hypertension, diabetes mellitus, metabolic syndrome, and cardiovascular diseases [1]. Several genome-wide association studies (GWASs) have identified genes that may be causally associated with uric acid levels, including the ATP-binding cassette, subfamily G, member 2 (ABCG2) gene (MIM 603756) [2-7]. Replication studies of $A B C G 2$ variants have been performed in Western and Asian countries [8, 9]. Okada et al. [4] identified a significant association between the rs2725220 single-nucleotide polymorphism (SNP) on chromosome 4q22 and uric acid levels.

The ABCG2 protein is a high-capacity transporter for uric acid excretion in the kidney, liver, and gut $[10,11]$. In this study, we analyzed the relationship between uric acid levels and the ABCG2 SNP rs2725220 using a group of volunteers from the Korean Metabolic Syndrome Research Initiative Study in Seoul. We also analyzed the association of the $A B C G 2$ SNP with body mass index and waist circumference levels.

\section{Methods}

\section{Study population}

Subjects for the GWAS were recruited from the Korean Metabolic Syndrome Research Initiative Study in Seoul City, which was initiated in December 2005. A total of 9,128 individuals were recruited in 2006, and an additional 17,569 individuals were recruited in 2007 [12-14]. Therefore, the total Seoul City cohort included 26,697 volunteers. Volunteers from the first round underwent routine health examinations at the health promotion centers in university hospitals between January 2006 and December 2007. From 
this total, 6,563 individuals were randomly selected for measurement of adiponectin levels. The subject characteristics were described in a previous study [14]. In brief, of the 6,563 individuals whose adiponectin was measured, 1,004 individuals were genotyped. The 1,004 subjects were all healthy individuals and were not undergoing any treatment for hyperuricemia. The Institutional Review Board of Human Research of Yonsei University approved the protocols of this study, and written informed consent was obtained from all subjects prior to enrollment.

\section{Data collection}

Participants were interviewed using a structured questionnaire to collect a personal history of cigarette smoking (never smoked, ex-smoker, or current smoker) and demographic characteristics (age, gender, etc.). Waist circumference was measured midway between the lower rib and iliac crest. For measurements of weight and height, light clothing was worn. Body mass indices were calculated as the subject's weight $(\mathrm{kg})$ divided by the square of the subject's height $\left(\mathrm{m}^{2}\right)$.

For clinical chemistry assays, serum was separated from peripheral venous blood samples obtained from each participant after a 12 -hour fast and stored at $-70^{\circ} \mathrm{C}$. Biomarkers of metabolic syndrome, including fasting blood glucose, total cholesterol, triglycerides, and high-density lipoprotein cholesterol, and uric acid levels were measured. Quality control of the data was conducted in accordance with the procedures recommended by the Korean Association of Laboratory Quality Control.

\section{Genotyping assays}

Samples from the Seoul City cohort were genotyped on the Affymetrix Genome-Wide Human SNP Array 5.0 (Affymetrix Inc., Santa Clara, CA, USA) at DNALink. For the data obtained from this chip, internal quality control (QC) measures were used: the QC call rate (Dynamic Model algorithm) always exceeded $86 \%$. Genotype calling was carried out using the Birdseed (v2) algorithm. A total of 1,004 individuals were genotyped using this platform. Ten of the 1,004 individuals were removed due to low genotyping call rates $(<95 \%)$. Three individuals were excluded due to failed genotyping of rs2725220, leaving a total of 991 individuals for the study.

\section{Statistical analysis}

Data were expressed as means \pm standard deviation (SD). Most statistical analyses were performed using PLINK and SAS (version 9.2; SAS Institute, Cary, NC, USA). The ABCG2 gene SNP rs2725220 was selected using the Affymetrix Genomewide Human SNP Array 5.0.
Each SNP was tested for possible effects on uric acid levels under an additive model. The multivariate linear regression models used in the study incorporated covariates (age and sex). Multiple logistic regression analysis was also performed. Odds ratios (ORs) with 95\% confidence intervals (CIs) were calculated to examine the association of the $A B C G 2$ SNP with abnormal uric acid levels ( $\geq 7 \mathrm{mg} / \mathrm{dL}$ for men and $\geq 6 \mathrm{mg} / \mathrm{dL}$ for women). All statistical tests were two-sided, and the statistical significance was determined as $\mathrm{p}<0.05$.

\section{Results}

The majority of individuals in this study was middle-aged (Table 1). This sample of Korean volunteers had low uric acid levels on average. Mean levels of uric acid in the dataset were higher in males $(6.23 \mathrm{mg} / \mathrm{dL})$ than in females $(4.21 \mathrm{mg} / \mathrm{dL})$. The percentage of individuals with abnormal uric acid levels ( $\geq 7.0 \mathrm{mg} / \mathrm{dL}$ ) was $14.7 \%$ for the Seoul City sample. The percentage of current smokers in the Seoul City dataset was $46.4 \%$ among male subjects and 3.9\% among female subjects.

Table 2 shows the p-values from a linear regression model for uric acid levels in the cohort sample, with age and sex included as covariates in the model. The rs2725220 SNP in the $A B C G 2$ gene was found to be associated with mean uric acid levels (effect per allele $0.25 \mathrm{mg} / \mathrm{dL}, \mathrm{p}<0.0001$ ), which was significant after Bonferroni correction ( $p=0.00025)$. The minor allele frequency of rs2725220 was 0.222 , and Hardy-Weinberg equilibrium was satisfied $(p=0.7079)$.

Table 1. General characteristics of the study population

\begin{tabular}{|c|c|c|}
\hline \multicolumn{2}{|c|}{ Subjects } & Subjects in Seoul City \\
\hline \multicolumn{2}{|l|}{ No. } & 991 \\
\hline \multicolumn{2}{|l|}{ Male gender $(\%)$} & 56.3 \\
\hline \multicolumn{2}{|c|}{ Age $(y)$} & $41.5 \pm 8.5$ \\
\hline \multicolumn{2}{|c|}{ Waist circumference (cm) } & $81.1 \pm 9.7$ \\
\hline \multicolumn{2}{|c|}{ Body mass index $\left(\mathrm{kg} / \mathrm{m}^{2}\right)$} & $23.7 \pm 3.1$ \\
\hline \multicolumn{2}{|c|}{ Fasting blood sugar (mg/dL) } & $93.8 \pm 16.4$ \\
\hline \multicolumn{2}{|c|}{ Systolic blood pressure (mm Hg) } & $120.8 \pm 13.8$ \\
\hline \multicolumn{2}{|c|}{ Diastolic blood pressure (mm Hg) } & $73.8 \pm 10.4$ \\
\hline \multicolumn{2}{|c|}{ HDL-cholesterol (mg/dL) } & $54.2 \pm 12.9$ \\
\hline \multicolumn{2}{|c|}{ LDL-cholesterol (mg/dL) } & $108.7 \pm 29.2$ \\
\hline \multicolumn{2}{|c|}{ Triglyceride (mg/dL) } & $118.0 \pm 93.5$ \\
\hline \multicolumn{2}{|l|}{ Uric acid (mg/dL) } & $5.34 \pm 1.50$ \\
\hline \multirow[t]{3}{*}{ Smoking status } & Non-smoker & $549(55.4)$ \\
\hline & Ex-smoker & $166(16.7)$ \\
\hline & Current smoker & $276(27.9)$ \\
\hline \multirow[t]{2}{*}{ Uric acid (mg/dL) } & Normal $(<7.0)$ & $845(85.3)$ \\
\hline & Abnormal $(\geq 7.0)$ & $146(14.7)$ \\
\hline
\end{tabular}


Table 2. Association of ABCG2 gene SNP rs2725220 with uric acid levels and lipid levels based on a linear regression model

\begin{tabular}{|c|c|c|c|c|c|}
\hline \multirow{2}{*}{ Phenotype } & \multicolumn{3}{|c|}{ Genotype (mean \pm SD) } & \multirow{2}{*}{$\begin{array}{c}\text { Effect } \\
(\mathrm{mg} / \mathrm{dL})\end{array}$} & \multirow{2}{*}{ p-value ${ }^{*}$} \\
\hline & GG $(n=601)$ & $G C(n=340)$ & $C C(n=50)$ & & \\
\hline Uric acid (mg/dL) & $5.26 \pm 1.39$ & $5.41 \pm 1.59$ & $5.93 \pm 1.94$ & 0.25 & $<0.0001$ \\
\hline HDL-cholesterol (mg/dL) & $53.6 \pm 12.6$ & $55.5 \pm 13.3$ & $52.7 \pm 12.9$ & 0.71 & 0.2631 \\
\hline Triglyceride (mg/dL) & $117.9 \pm 85.2$ & $115.0 \pm 94.5$ & $138.9 \pm 159.9$ & 3.46 & 0.4679 \\
\hline LDL-cholesterol (mg/dL) & $108.9 \pm 29.5$ & $107.8 \pm 28.4$ & $113.9 \pm 31.2$ & 0.77 & 0.6179 \\
\hline
\end{tabular}

Estimated effect size $(\beta)$ and p-value in the multiple linear regression model considering age and sex under an additive model. SNP, single-nucleotide polymorphism; SD, standard deviation; HDL, high-density lipoprotein; LDL, low-density lipoprotein.

Table 3. Odds ratio (OR) of polymorphic genotypes of ABCG2 gene SNP rs2725220 on uric acid levels in Seoul City data ( $\mathrm{n}=991)$

\begin{tabular}{|c|c|c|c|c|c|}
\hline \multirow{2}{*}{ Subject } & \multirow{2}{*}{ Genotype } & \multirow{2}{*}{$\begin{array}{c}\text { Normal }(<7.0 \mathrm{mg} / \mathrm{dL})^{\mathrm{b}} \\
\text { No. }(\%)\end{array}$} & \multicolumn{3}{|c|}{ Abnormal $(\geq 7.0 \mathrm{mg} / \mathrm{dL})^{b}$} \\
\hline & & & No. (\%) & OR $(95 \% \mathrm{Cl})$ & p-value \\
\hline \multirow[t]{2}{*}{ All } & GG & $527(62.4)$ & $74 \quad(50.7)$ & 1.00 (reference) & \\
\hline & $\mathrm{GC} / \mathrm{CC}$ & $318(37.6)$ & $72(49.3)$ & $1.78(1.22-2.62)$ & 0.0031 \\
\hline \multirow[t]{2}{*}{ Men } & GG & $269(65.1)$ & $73(50.3)$ & 1.00 (reference) & \\
\hline & GC/CC & $144(34.9)$ & $72(49.7)$ & $1.82(1.24-2.68)$ & 0.0023 \\
\hline \multirow[t]{2}{*}{ Women } & GG & $253(60.2)$ & $6(46.2)$ & 1.00 (reference) & \\
\hline & $\mathrm{GC} / \mathrm{CC}$ & $167(39.8)$ & $7(53.8)$ & $1.75(0.58-5.31)$ & 0.3215 \\
\hline
\end{tabular}

SNP, single-nucleotide polymorphism; $\mathrm{Cl}$, confidence interval.

${ }^{\mathrm{a}}$ Adjusted for age and sex; ${ }^{\mathrm{b}}$ Abnormal $(\geq 6.0 \mathrm{mg} / \mathrm{dL})$ and normal $(<6.0 \mathrm{mg} / \mathrm{dL})$ were used for women.

Table 4. Odds ratio (OR) of polymorphic genotypes of ABCG2 gene SNP rs2725220 on uric acid levels ${ }^{\mathrm{a}}$ in Korean men ( $\left.\mathrm{n}=558\right)$

\begin{tabular}{|c|c|c|c|c|c|c|}
\hline \multirow{2}{*}{ Subject } & & \multirow{2}{*}{ Genotype } & \multirow{2}{*}{$\begin{array}{c}\text { Normal }(<7.0 \mathrm{mg} / \mathrm{dL}) \\
\text { No. }(\%)\end{array}$} & \multicolumn{3}{|c|}{ Abnormal $(\geq 7.0 \mathrm{mg} / \mathrm{dL})$} \\
\hline & & & & No. (\%) & OR $(95 \% \mathrm{Cl})$ & p-value \\
\hline \multirow[t]{8}{*}{ BMI $\left(\mathrm{kg} / \mathrm{m}^{2}\right)$} & $<22.65$ & GG & $72(62.6)$ & $13(54.2)$ & 1.00 (reference) & \\
\hline & & $\mathrm{GC} / \mathrm{CC}$ & $43(37.4)$ & $11(45.8)$ & $1.41(0.58-3.43)$ & 0.4456 \\
\hline & $<24.3$ & GG & $71(64.0)$ & $13(44.8)$ & 1.00 (reference) & \\
\hline & & $\mathrm{GC} / \mathrm{CC}$ & $40(36.0)$ & $16(55.2)$ & $2.13(0.93-4.89)$ & 0.0748 \\
\hline & $<26.4$ & GG & $63(60.0)$ & $25(71.4)$ & 1.00 (reference) & \\
\hline & & $\mathrm{GC} / \mathrm{CC}$ & $42(40.0)$ & $10(28.6)$ & $0.60(0.26-1.38)$ & 0.2263 \\
\hline & $\geq 26.4$ & GG & $63(76.8)$ & $22(38.6)$ & 1.00 (reference) & \\
\hline & & GC/CC & $19(23.2)$ & $35(61.4)$ & $5.09(2.41-10.8)$ & $<0.0001$ \\
\hline \multirow[t]{8}{*}{ WC $(\mathrm{cm})$} & $<80$ & GG & $71(64.0)$ & $10(55.6)$ & 1.00 (reference) & \\
\hline & & $\mathrm{GC} / \mathrm{CC}$ & $40(36.0)$ & $8(44.4)$ & $1.42(0.52-3.89)$ & 0.4956 \\
\hline & $<86$ & GG & $73(61.3)$ & $15(48.4)$ & 1.00 (reference) & \\
\hline & & $\mathrm{GC} / \mathrm{CC}$ & $46(38.7)$ & $16(51.6)$ & $1.68(0.76-3.74)$ & 0.2016 \\
\hline & $<91$ & GG & $65(69.2)$ & 17 (51.5) & 1.00 (reference) & \\
\hline & & $\mathrm{GC} / \mathrm{CC}$ & $29(30.8)$ & $16(48.5)$ & $1.98(0.87-4.54)$ & 0.1054 \\
\hline & $\geq 91$ & GG & $60(67.4)$ & $31(49.2)$ & 1.00 (reference) & \\
\hline & & $\mathrm{GC} / \mathrm{CC}$ & $29(32.6)$ & $32(50.8)$ & $2.10(1.08-4.10)$ & 0.0299 \\
\hline
\end{tabular}

$\mathrm{SNP}$, single-nucleotide polymorphism; $\mathrm{Cl}$, confidence interval; $\mathrm{BMI}$, body mass index; $\mathrm{WC}$, waist circumference.

${ }^{a}$ Adjusted for age.

We also analyzed the association of rs2725220 with abnormal uric acid levels (Table 3). Subjects with the GC/CC genotype had a 1.78-fold (range, 1.22- to 2.62-fold) higher risk of having abnormal uric acid levels $(\geq 7.0 \mathrm{mg} / \mathrm{dL})$ than subjects with the GG genotype. When analyzed by gender, the association with ABCG2 was stronger in men than in women. In Table 4, we analyzed the association of ABCG2 by body mass index (BMI) quartile levels and waist circumference quartile levels in male subjects. The association with ABCG2 was much stronger in male subjects with BMI $\geq$ 
26.4 (OR, 5.09; 95\% CI, 2.41 to 10.8) than in male subjects with BMI $<26.4$. The association with ABCG2 was also a little bit stronger in male subjects with waist circumference (WC) $\geq 91$ (OR, 2.10; 95\% CI, 1.08 to 4.10) than in male subjects with WC $<91$.

\section{Discussion}

In a cohort study of 991 subjects, an $A B C G 2$ gene SNP was associated with increased uric acid, consistent with previous studies. Several GWASs have reported that $A B C G 2$ exerts a major influence on uric acid levels [2, 3, 6, 7]. Dehghan et al. [6] conducted a genomewide study in which an SNP in the $A B C G 2$ gene, rs2231142, displayed strong evidence of an association with uric acid levels $\left(\mathrm{p}<10^{-60}\right)$. Another GWAS also reported that rs2231142 showed a strong association with uric acid levels $\left(p=5.1 \times 10^{-6}\right)$ [2]. More recently, a GWAS in European-American obesity cases and controls reported significant genome-wide association of two SNPs with uric acid levels: rs2622605 and rs1481017 [3]. Another recent GWAS also reported a strong association between rs2231142 and uric acid levels $\left(\mathrm{p}=3.34 .1 \times 10^{-42}\right)$ [7].

In the present study, rs2725220 was found to have a strong association with uric acid levels. In agreement with these findings, a recent study reported that rs 2725220 was strongly associated with uric acid levels (effect per allele $-0.135 \mathrm{mg} / \mathrm{dL}, \mathrm{p}=4.2 \times 10^{-30}$ ) [4]. Several recent studies reported that the association between serum uric acid and the allelic effects of SNPs in ABCG2 was sex-specific [8, 9]. In a recent study of 4 US populations, the association between rs2231142 and serum uric acid was significantly stronger in men and postmenopausal women compared to their premenopausal counterparts [9]. In the present study, the association of the $A B C G 2$ gene SNP with uric acid was stronger in men than in women.

Associations between genotypes and phenotypes can be modified by gene-environment interactions. A modification of the effect of the associations between ABCG2 SNPs and serum uric acid concentrations by interactions with obesity has been reported [3, 9]. In a recent study of 4 US populations, the association between rs2231142 and serum uric acid was stronger in normal-weight subjects than in obese subjects [9]. In the present study, we also examined the association of the $A B C G 2$ SNP with uric acid levels according to BMI level and waist circumference. The association was stronger in subjects with a high BMI and high WC levels than in subjects with a low BMI and low WC levels.

The ABCG2 gene encodes a membrane transporter belonging to the ATP-binding cassette superfamily of membrane transporters, a group involved in the trafficking of biological molecules across cell membranes. The ABCG2 gene contains 16 exons and spans over $66 \mathrm{~kb}$ [15]. Allikmets et al. [16] mapped the ABCG2 gene to human chromosome 4q22 using radiation hybrid analysis.

Candidate gene analysis suffers from population substructure. We estimated the identity by state over all SNPs, and only four individuals were shown to be biological relatives. Genetic studies in Asian populations may not identify the same set of genes as those in European populations [17]. Nevertheless, the Seoul City cohort study in Korean populations indicates that the $A B C G 2$ gene on chromosome 4 is associated with serum uric acid levels, as is the case in several other populations.

\section{Acknowledgments}

This research was supported by the Basic Science Research Program through the National Research Foundation of Korea (NRF), funded by the Ministry of Education, Science and Technology (2012010044).

\section{References}

1. Richette P, Bardin T. Gout. Lancet 2010;375:318-328.

2. Karns R, Zhang G, Sun G, Rao Indugula $S$, Cheng $H$, Havas-Augustin D, et al. Genome-wide association of serum uric acid concentration: replication of sequence variants in an island population of the Adriatic coast of Croatia. Ann Hum Genet 2012;76:121-127.

3. Li WD, Jiao H, Wang K, Zhang CK, Glessner JT, Grant SF, et al. A genome wide association study of plasma uric acid levels in obese cases and never-overweight controls. Obesity (Silver Spring) 2013;21:E490-E494.

4. Okada Y, Sim X, Go MJ, Wu JY, Gu D, Takeuchi F, et al. Meta-analysis identifies multiple loci associated with kidney function-related traits in east Asian populations. Nat Genet 2012;44:904-909.

5. Kolz M, Johnson T, Sanna S, Teumer A, Vitart V, Perola M, et al. Meta-analysis of 28,141 individuals identifies common variants within five new loci that influence uric acid concentrations. PLoS Genet 2009; 5:e1000504.

6. Dehghan A, Köttgen A, Yang Q, Hwang SJ, Kao WL, Rivadeneira F, et al. Association of three genetic loci with uric acid concentration and risk of gout: a genome-wide association study. Lancet 2008;372:1953-1961.

7. Yang B, Mo Z, Wu C, Yang H, Yang X, He Y, et al. A genome-wide association study identifies common variants influencing serum uric acid concentrations in a Chinese population. BMC Med Genomics 2014;7:10.

8. Takeuchi F, Yamamoto K, Isono M, Katsuya T, Akiyama K, Ohnaka K, et al. Genetic impact on uric acid concentration and hyperuricemia in the Japanese population. J Atheroscler Thromb 2013;20:351-367.

9. Zhang L, Spencer KL, Voruganti VS, Jorgensen NW, Fornage 
M, Best LG, et al. Association of functional polymorphism rs2231142 (Q141K) in the ABCG2 gene with serum uric acid and gout in 4 US populations: the PAGE Study. Am J Epidemiol 2013;177:923-932.

10. Matsuo H, Takada T, Ichida K, Nakamura T, Nakayama A, Ikebuchi Y, et al. Common defects of ABCG2, a high-capacity urate exporter, cause gout: a function-based genetic analysis in a Japanese population. Sci Transl Med 2009;1:5ra11.

11. Saison C, Helias V, Ballif BA, Peyrard T, Puy H, Miyazaki T, et al. Null alleles of $A B C G 2$ encoding the breast cancer resistance protein define the new blood group system Junior. Nat Genet 2012;44:174-177.

12. Sull JW, Kim HJ, Yun JE, Kim G, Park EJ, Kim S, et al. Serum adiponectin is associated with family history of diabetes independently of obesity and insulin resistance in healthy Korean men and women. Eur J Endocrinol 2009;160:39-43.

13. Yoon SJ, Lee HS, Lee SW, Yun JE, Kim SY, Cho ER, et al. The as- sociation between adiponectin and diabetes in the Korean population. Metabolism 2008;57:853-857.

14. Jee SH, Sull JW, Lee JE, Shin C, Park J, Kimm H, et al. Adiponectin concentrations: a genome-wide association study. Am J Hum Genet 2010;87:545-552.

15. Bailey-Dell KJ, Hassel B, Doyle LA, Ross DD. Promoter characterization and genomic organization of the human breast cancer resistance protein (ATP-binding cassette transporter G2) gene. Biochim Biophys Acta 2001;1520:234-241.

16. Allikmets R, Schriml LM, Hutchinson A, Romano-Spica V, Dean M. A human placenta-specific ATP-binding cassette gene $(A B C P)$ on chromosome $4 \mathrm{q} 22$ that is involved in multidrug resistance. Cancer Res 1998;58:5337-5339.

17. Deurenberg P, Yap M, van Staveren WA. Body mass index and percent body fat: a meta analysis among different ethnic groups. Int J Obes Relat Metab Disord 1998;22:1164-1171. 